\title{
CERRANDO UN PROGRAMA ICONOGRÁFICO. LAS HIJAS DE JOB EN LA CAPILLA DE LA VIRGEN DE GUADALUPE EN LAS DESCALZAS REALES DE MADRID
}

\author{
UNDERSTANDING AN ICONOGRAPHICAL PROGRAM. THE DAUGHTERS \\ OF JOB IN THE CHAPEL OF THE VIRGIN OF GUADALUPE \\ IN THE ROYAL DISCALCED CLARISSE ORDER OF MADRID
}

\author{
Begoña Álvarez Seijo \\ Universidade de Santiago de Compostela
}

ABSTRACT • The Chapel of the Virgin of Guadalupe, located in the Monastery of the Royal Discalced Nuns of Madrid, features a complex iconographical program, with the Virgin and the strong women of the Old Testament as its protagonists. This program was executed by the artist Sebastián Herrera Barnuevo, and designed by one of its resident nuns, Sister Ana Dorotea de Austria. This article attempt to shed light an a rather uncommon feminine typology: that of the daughters of Job, Jemima and Keren-happuch by means of the study of the principal literary sources where they are mentioned. By this means I will offer a complete reading of the Chapel's iconographical program, by establishing the relationship between the depictions of Día and the Immaculate Conception, and Alcohol and Bathsheba.

KEYWORDS: Royal Discalced; Strong Women of the Old Testament; Daughters of Job; Immaculate Conception; Bathsheba; Iconography.

RESUMEN • La capilla de la Virgen de Guadalupe, situada en el Monasterio de las Descalzas Reales de Madrid, se compone de un complejo programa iconográfico, protagonizado por la Virgen y las mujeres fuertes del Antiguo Testamento, realizado por el artista Sebastián Herrera Barnuevo e ideado por una monja allí residente, Sor Ana Dorotea de Austria. El presente trabajo pretende arrojar luz sobre una tipología femenina poco común, la de las hijas de Job, Día o Mañana y Alcohol, a través de un estudio de las principales fuentes literarias en las que aparecen mencionadas, para con ello ofrecer una lectura total del programa iconográfico de la capilla, al establecerse una relación entre las representaciones de Día y la Inmaculada Concepción y Alcohol y Betsabé.*

PALABRAS CLAVES: Descalzas Reales; mujeres fuertes del Antiguo Testamento; hijas de Job; Inmaculada Concepción; Betsabé; iconografía.

Fecha recepción: 11-3-2019 / Fecha aceptación: 30-8-2019

* Este trabajo no habría sido posible sin el inestimable asesoramiento de la profesora Carme López Calderón, del profesor José Manuel López Vázquez, de la Universidad de Santiago de Compostela, y la colaboración de la conservadora de Patrimonio Nacional Ana García Sanz. 


\section{EL PROGRAMA ICONOGRÁFICO DE SOR ANA DOROTEA. ESTADO DE LA CUESTIÓN}

En el claustro alto del monasterio de Nuestra Señora de la Consolación, popularmente conocido como las Descalzas Reales, se encuentra una auténtica joya del barroco: un altarretablo dedicado a la Virgen de Guadalupe, realizado por el arquitecto, tracista y pintor Sebastián Herrera Barnuevo, cuya mentora fue una monja residente en el monasterio, Sor Ana Dorotea de Austria.

El camarín se encuentra instalado en el muro del ala este del claustro; está cubierto por una bella y tupida celosía de madera decorada con motivos vegetales, sobre la cual dos grandes águilas, emblema de la Casa Habsburgo, portan una inscripción que nos indica su fecha de ejecución y quién fue su promotora: «Surgere quam cernis speciosis cullibus ara mentis honos, animi pignus amoris opus quos heroniniae sacrae pepereret triumphos Mariae adscribit laudibus arte potens filia Rodulfi pietati insignis, etarmis, nobilior Christo quam Dorothea dicta. Plena sub hoc uno tot vive nomine gesta ni Maria daret non habitura decus. Anno MDCLIII»' . (Sánchez Hernández, 2014: 494).

El programa iconográfico que guarda este retablo-casillero se compone de 73 espejos pintados, insertos en molduras de madera tallada y dorada, divididos en dos espacios--el

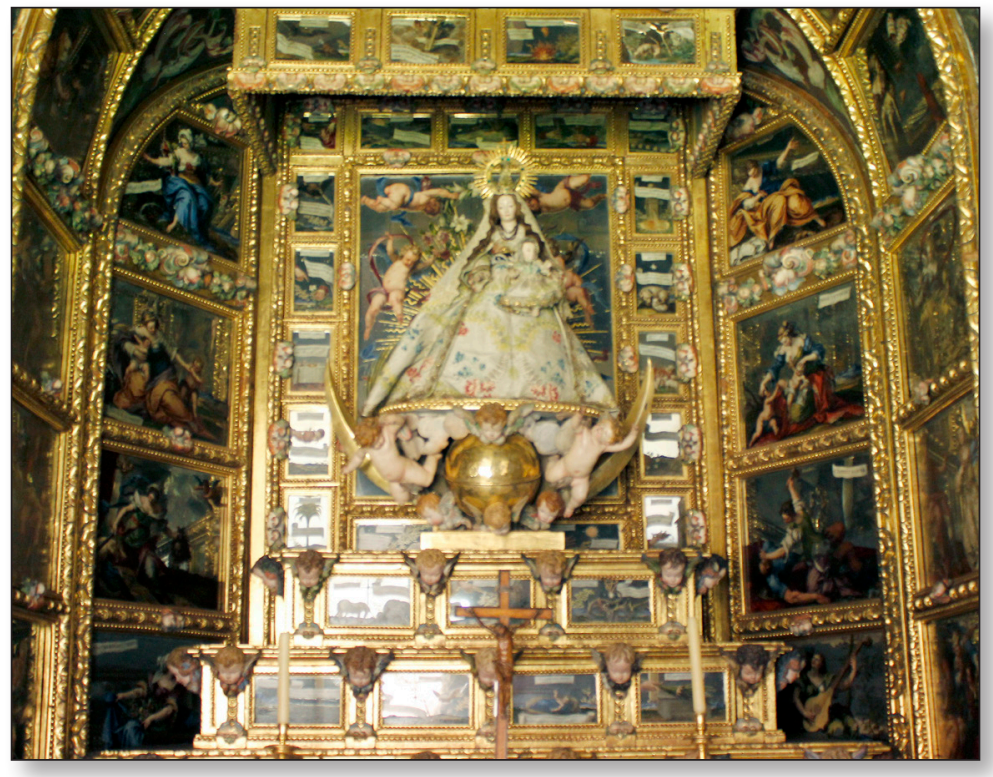

Fig.1. Sebastián de Herrera Barnuevo, Capilla de la Virgen de Guadalupe. Madrid, Monasterio de las Descalzas Reales (Patrimonio Nacional). retablo y la hornacina que lo envuelve--, la imagen de la Virgen de Guadalupe centrando el conjunto $^{2}$ y una mesa de bronce. Los 51 vidrios que se disponen por el interior del retablo representan la vida y virtudes de la Virgen a través de otros tantos emblemas; de los 22 paneles restantes, los 21 que se disponen por la hornacina representan a las mujeres fuertes del Antiguo Testamento y, el espejo restante, el de mayor tamaño, representa a la Inmaculada Concepción y centra el frontal de altar [fig.1].

1. «El altar que contemplas en hermosas ceremonias, honor de la mente, dedicación del alma, trabajo del amor, describe el triunfo de las heroínas sagradas ejecutado en alabanza a María. Dorotea, versada en el arte, hija de Rodolfo, que fue destacado en piedad y distinguido en guerra en el servicio de Cristo, lo dedica. Bajo este nombre de María todos los hechos sobreviven, los cuales no habrían alcanzado la gloria sino por la gracia de María. Año de 1653».(Sánchez Hernández, 2014: 494).

2. Hoy en día la imagen que se encuentra en la capilla es una Inmaculada Concepción, ya que la original Virgen de Guadalupe realizada por Herrera Barnuevo fue sustituida en fecha desconocida. 
Por tanto, estamos ante un discurso iconográfico femenino, ideado por una mujer, dedicado a mujeres y con la mujer como única protagonista, con el cual se perseguía una doble finalidad: por un lado, exaltar el dogma de la Inmaculada Concepción y posicionar a la Casa de Austria a favor del mismo y, por otro, representar modelos femeninos de comportamiento que sirviesen de referencia a las clarisas descalzas que habitaban en el monasterio, ejemplificados tanto en la Virgen María como en las mujeres fuertes del Antiguo Testamento (Sánchez Hernández, 2014).

Pictóricamente lo más destacado del conjunto son los espejos que representan a las mujeres fuertes y a la Inmaculada Concepción, por su calidad técnica e importante valor iconográfico e iconológico. Para la elaboración de este programa, Sor Ana Dorotea se inspira en el libro de Martín Carrillo Elogio de las mujeres insignes del viejo testamento (1627), escrito por encargo de su tía, también profesa en las Descalzas Reales, Sor Margarita de la Cruz. El libro lo conforman 47 capítulos dedicados a las ilustres mujeres de la Biblia, extrayendo los textos de la Vulgata y rematando cada uno de ellos con un soneto de un poeta de la época (Sánchez Hernández, 2016: 141). De esta obra, Sor Ana Dorotea escoge 18 de las 47 mujeres presentes en el libro de Carrillo para que Sebastián de Herrera Barnuevo las ejecute en los espejos que enmarcan el retablo y en el intradós del arco de medio punto. Prácticamente la totalidad de los espejos cuentan con el texto dorado que identifica a cada una de las mujeres allí presentes, agilizando su identificación por parte del espectador, y con una filacteria en referencia a su historia. Las únicas mujeres ejemplares que no aparecen en la obra de Carrillo y que están presentes en la capilla son Axa, Alcohol y Día o Mañana, hijas de Job, y La Inmaculada Concepción.

El conjunto presenta un modo de lectura complejo pues, como proponen por primera vez Wethey y Sunderland (1966), la hornacina se estructura mediante parejas mujeres, que se relacionan iconográfica o iconológicamente, es decir, dependiendo del caso, la relación tendría que ver con la forma en la que están representadas o con la historia y mensaje que transmiten, comenzándose dicha lectura por el espejo del extremo inferior derecho. Estos autores proponen que los espejos que se disponen en los tres primeros niveles, antes de llegar al inmediatamente anterior al intradós, hacen pareja con otro de los paneles que se encuentra en el lado opuesto, de modo que al espejo exterior de un lado del altar-retablo le correspondería el exterior del contrario, y los dos internos, a su vez, estarían relacionados (Wethey y Sunderland, 1966: 20). De este modo Abigail y David hace pareja con Rebeca; Abisag con María, hermana de Moisés; La Reina de Saba con Esther ante Asuero; Judith con la cabeza de Holofernes haría correspondencia con Jael y Sísara; y por último, en el tercer nivel, La madre de Sansón estaría emparejada con Débora, y Sara con Isaac e Ismael formaría pareja con Raquel con José y Benjamín. La lectura de las parejas se complica en el cuarto nivel, si seguimos las propuestas de Wethey y Sunderland (1966) y Díaz García (2010), pues dejan de formar pareja como lo habían hecho en los niveles anteriores: los espejos interiores siguen interrelacionándose pero, sin embargo, los exteriores forman pareja con el espejo que se encuentra sobre ellos, los cuales ya forman parte del intradós del arco. Así Noema haría pareja con Axa, pero La sunamita con Eliseo estaría emparejada con Anna, la madre de Samuel que está sobre ella, y lo mismo ocurriría con La viuda sarepta y Elías, que haría pareja con Ruth, que está entregando un ramo de espigas a Noemí. De este modo, para estos autores Alcohol, hija de Job haría pareja con Betsabé coronando a Salomón, quedando tan solo sin correspondencia el espejo de Día o mañana, hija de Job, situado en la clave del arco, sin dar ninguna explicación sobre la correspondencia entre Betsabé y Alcohol o sobre la soledad del espejo de Día (Wethey y Sunderland, 1966: 21; Díaz García, 2010: 38). 
Sánchez Hernández (2014: 503-505) difiere de la propuesta anterior y ofrece otra solución para la correspondencia de los espejos de estas mujeres ejemplares. Según su lectura los tres primeros niveles seguirían la relación establecida por Wethey, Sunderland y Díaz García, pero el cuarto nivel continuaría la lógica de los tres anteriores haciendo pareja Noema y Axa, en los espejos interiores, y La sunamita y Eliseo con La viuda sarepta y Elías. De este modo, ya en el intradós del arco de medio punto, al espejo de Anna, la madre de Samuel le correspondería el de Ruth en el lado contrario, y Alcohol, hija de Job haría lo propio con Betsabé coronando a Salomón. Por su parte, apunta que Día o mañana, hija de Job, se encuentra en eje con la imagen de la Virgen que descansa sobre un rompiente de nubes y culmina en el espejo octogonal del frontal de altar donde se ubica la Inmaculada Concepción. Esta misma posibilidad la contemplan Alba y Seijas (2015: 121-122) que proponen que esta línea vertical con Día, la Virgen de Guadalupe y la Inmaculada Concepción simbolice la Biblia en su totalidad, desde el Génesis al Apocalipsis pues, si bien el disco solar que porta Día es un símbolo relacionado con la Inmaculada, la disposición de la hija de Job surgiendo entre las nubes, en su propuesta, podría ser una alusión a la creación, ya que observan un paralelismo iconográfico entre la representación de Día con la forma en la que se representa Dios en la creación del mundo.

\section{LAS HIJAS DE JOB: TRES GRANDES DESCONOCIDAS}

La representación de las hijas de Job no es un tema recurrente dentro de la iconografía de la Edad Moderna; esto se puede deber precisamente a su historia o, más bien, a la falta de la misma. Las tres hijas de Job aparecen únicamente mencionadas en la Sagrada Biblia dentro del marco narrativo del Libro de Job, en dos ocasiones. En la primera, tan solo se indica su número, mientras que en la segunda, a diferencia de a sus siete hermanos, se les otorga un nombre y se resalta su belleza concediéndoles, de este modo, protagonismo sobre sus homólogos varones (Alba y Seijas, 2015: 113): «Tuvo siete hijos y tres hijas: la primera se llamaba Paloma, la segunda Acacia; la tercera Azabache. No había en todo el país mujeres más bellas que las hijas de Job. Su padre les repartió heredades como a sus hermanos» (Jb, 42,13-15). De este modo, lo que se destaca de estas mujeres es que poseen un nombre propio los cuales, sin embargo, varían notablemente según la fuente a la que se recurra, por lo que será en un estudio de los mismos donde residirá la clave para comprender cómo son representadas en la capilla de la Guadalupe.

En la Nueva Biblia española (Schökel y Mateos, 1975), así como en el resto de las ediciones contemporáneas de las sagradas escrituras (Torres Amat, 2010), se las denomina Paloma, Acacia y Azabache; estos nombres son una posible traducción del texto de la Biblia hebrea, en el que se las llama Yemimah [Paloma], Qetsiah [Acacia] y Qeren Happuk [Azabache], que, sin embargo, en la Septuaginta el traductor interpreta como Hemera, Casia y Cuerno de Amaltea, derivando la denominación hebrea de la hija mayor, Yemimah, de yom que significa día, adaptando el apelativo de la tercera, Qeren Happuk, que en hebreo hace referencia a un tarro o cuerno de afeites, como Cuerno de Amaltea, también llamado cornucopia, en referencia al cuerno de la abundancia de la mitología griega. Por su parte, en la traducción aramea del libro de Job, el Targum de Job $(42,14)$, se emplea el término hebreo pero dotándolo de una explicación, siendo la primera Yemimá por ser hermosa como la luz del día, la segunda Keziá, por tener un exquisito aroma como el que posee la Casia, y la tercera Keren 
Happuk, por tener una cara con el brillo propio de la esmeralda ${ }^{3}$ (Alba y Seijas, 2015: 114115). Por su parte, en el Testamento de Job, texto apócrifo escrito aproximadamente en el siglo I a.C a modo de cuento tradicional judío, hagadá, que se basa en el Libro de Job para contar la historia de sus últimas voluntades, se les otorgan los mismos nombres que en la Septuaginta y, además de destacar su gran belleza, se resalta por primera vez la bondad de su corazón, indicando que bajo el cielo no se han hallado mujeres mejores que las hijas de Job, y se les concede un gran protagonismo en el momento de su muerte, al ser testigos junto a su padre de la teofanía (Spittler, 1983: 829-869).

No obstante, quizá uno de los mayores desarrollos de la etimología y motivo de las hijas de Job, el más relevante para el análisis que se pretende llevar a cabo de su iconografía en las Descalzas Reales, se encuentre en las exposiciones o explicaciones literarias y morales del Libro de Job, presentes en la literatura española desde el siglo $\mathrm{XVI}^{4}$ y durante los siglos XVII y XVIII. Sin duda la más conocida es la Exposición del libro de Job de Fray Luis de León, obra póstuma del moralista que se encontraba en el archivo de la Universidad de Salamanca y se publica por primera vez en Madrid en 1779 en la imprenta de Pedro Marín (San José Lera, 1992: 161-174). En esta obra el fraile agustino ofrece una traducción de los nombres de las hijas próxima a la de la Septuaginta: «Y tuvo siete hijos y tres hijas. Y llamó el nombre de la primera Jemina (día), y de la segunda Quezia (caia), y el de la tercera Qeren Hapuch (cornia, cornucopia). No se hallaron en toda la tierra mujeres más hermosas que las hijas de Job, y dióles su padre heredad entre sus hermanos" (León, 1779: 900). Más información aporta en el ulterior comentario, en el que trata de explicar en detalle el por qué y significado de estos nombres para las hijas de Job:

Más veamos lo que sigue. Y llamó el nombre de la una Jemina, y de la segunda Quezia, y de la tercera Queren Hapuch. Jemina viene de Jom, que es día; y Quezia es Casia, una especia aromática o de canela muy fina; Queren Hapuch es como decir cuerno de alcohol o de afeite. Que según esto podremos en español llamarlas Diana, Casilda y Cornelia [...] Pero vamos a la segunda duda que puse acerca del propósito y fin de estos nombres. En que de ordinario se dicen dos cosas: una, dice el parafraste caldeo que eran de extremada hermosura, como luego la Escritura lo dice, y que las llamó su padre así para declarar su hermosura en el nombre. Porque a Jamina, la primera, como dijimos es originada del día, la llamó así como si la llamase alba o aurora, en significación de gentileza y frescura. La segunda Quesia, fue como llamarla olorosa o fragante, y de estima y precio, cual es la casia y la canela. Y en la tercera, que llamó Qeren Hapuch, que significa bujeta de alcohol o de afeite, declaró ser ella la misma compostura o pintura, y como decir solemos, ser imagen pintada. (De León, 1779: 910-911). ${ }^{5}$

En su explicación ya aparece esa referencia al alcohol en relación al nombre de Queren Happuk, a la que también llama Cornelia o imagen de la pintura, además de la denominación

3. Se hace referencia a otra acepción del término puk en hebreo que haría referencia a una piedra preciosa de color azulado.

4. Sorprende el escaso número de comentarios al Libro de Job que se escriben durante el siglo XVI en España, sobre todo si lo comparamos con las abundantísimas declaraciones sobre otros libros del Antiguo y del Nuevo Testamento publicados en esta época, pues tan solo estarían In Job Commentaria de Fray Diego de Zúñiga (1584) y Commentariorum in Job libri tredecim de Juan de Pineda (1597).

5. De la traducción de los nombres que hace Fray Luis de León en su obra, así como la explicación que otorga para cada uno de ellos, se hace eco el padre Felipe Scío de San Miguel en su traducción de la Biblia Vulgata Latina, publicada en Valencia entre 1790 y 1793 y realizada por encargo del rey Carlos III, donde nombra a las hijas de Job: Día, Cassia y Cornustibia. (Scio de San Miguel, 1852: 577). 
de Jemima como originada del día, sumándole a las posibles traducciones del nombre Jemima las de Diana, Alba o Aurora.

Otra obra póstuma sobre el Libro de Job la encontramos de mano de Francisco de Quevedo y Villegas en la paráfrasis «La constancia y la paciencia del santo Job, en sus pérdidas, enfermedades y persecuciones" que se encuentra en Vida y obras póstumas de Francisco de Quevedo y Villegas, caballero del hábito de Santiago, secretario de su Magestad y señor de la villa de la Torre de Juan Abad (1794), que continua la misma línea de Fray Luis de León para la elección de los nombres de las hijas: «Hizo dios a Job padre del día en una hija; y porque no falten aromas de la Casia la segunda, y para que sobre todo lo precioso, le da en la tercera la abundancia, y el que llaman por eso cuerno de Amalthea, que se pinta brotando perfumes, en yerbas, rosas y flores». (Quevedo y Villegas, 1794: 551).

Con todo, y pese a la importancia de los dos autores anteriores, quizá el comentario del Libro de Job más relevante para el análisis del programa de Sor Ana Dorotea sea el redactado por Joseph Gallo ${ }^{6}$ (1621) ya que, por un lado, fue publicado en la época, mientras los dos anteriores no vieron la luz hasta el siglo XVIII; y por otro, debido también a la traducción que hace de los nombres y el análisis comparativo que realiza de las virtudes que refieren los mismos:

En los nombres que les puso Job a sus tres hijas se echaba de ver que eran muy hermosas. Pues la Esposa no tiene otro título que más declare su hermosura, que es de aurora, Sol y Luna, todo lo cual se halla en el nombre de Día, que es el de la primera. El de la segunda significa una yerba, o palo oloroso que fuera de su fragancia es de grande provecho. Título que también se dio la Esposa, o ella se tomó diciendo Como mirra de olor suave. El nombre de la tercera significa algún tipo de color que sirve para pintar el rostro haciéndole más hermoso (aunque sucio) que de suyo era; para dar a entender que era tan hermosa como si fuese pintada, según acá decimos, y que ella sin afeites, tenía el rostro bruñido. En llamar a la primea Día encerró toda su historia el santo Job, porque no fue más de un amanecer claro, con bienes de alma y cuerpo, anochecer oscuro, con trabajos de ambas partes; y un volver a amanecer sin nueva noche. Y según otros cuenta el día (conforme al lugar del Génesis) le contásemos nosotros, que es desde la víspera, se puede entender con toda propiedad, diciendo: que comenzó la víspera de Job con la luz de los primeros bienes, de la cual dijo que andaba en su cabeza y con mil tinieblas la seguía. Eso es con miedos de perderla, como después confesó, y le sucedió en noche de torbellinos y trabajos. Pero ya que pasó por ellos, y con la gracia de Dios, tornó a cobrar lo perdido sin miedo de perderlos, llama a la primera Día que es símbolo de gloria, en la cual no hay miedos de perderla. En la segunda hija nos quiso dar a entender que si se puede vivir esta vida sin sombras de la muerte es procurando ser yerbas olorosas para Dios, con fragancia de virtudes. Así se viene a llegar al nombre de la tercera y a cobrar el alma una hermosa sin afeites y un amor sin invenciones y quimeras, con seguridad de ánimo y temiendo ofender a dios, con el cual crecen las virtudes hasta llegar a gozarle. (Gallo, 1621: 1975-1976).

En este comentario Gallo no solo menciona los significados de los nombres de las hijas de Job, sino que establece una comparación de los mismos con las cualidades o virtudes de la Esposa, no pudiendo ser esta otra que la Virgen María, ya que la esposa de Job, únicamente con protagonismo en su testamento, destaca efectivamente por sus cualidades negativas. Además, esta relación de la luz de Día con la Virgen se vuelve apreciar en la segunda mención que hace Gallo, pues su nacer sin mácula se relaciona en multitud de ocasiones con el amanecer tras la prolongada noche después del pecado original. De la segunda, Quezia,

6. Es el más escolástico de los tres ejercicios aquí abordados; se trata de un comentario que ha pasado desapercibido para la crítica pero que, sin duda, representa el esfuerzo de un fraile por desentrañar el sentido del Libro de Job (Gutiérrez Mueller, 2013: 14). 
Casia, Acacia o Canela, dice que es de fragante olor, título que también se le dio a la Virgen al decir de ella que era Como mirra escogida exhalé suave olor (Si 24,15; Rigual, 1797: 11), título que recibe de la Iglesia al relacionarla con la mirra que preserva la corrupción del alma de los vicios del cuerpo (Ligorio, 1885: 277).

Sin embargo esta comparación con la Virgen la realiza Gallo con las dos primeras hijas de Job, no la realiza con la tercera, Queren Happuk, Cornucopia, Cornustibia, Cuerno de Amaltea, Azabache o Alcohol. A ella la relaciona con los productos que embellecen el cuerpo pero que, al mismo tiempo, lo ensucian, para dar a entender que su belleza era tan perfecta que parecía que la fomentaban ese tipo de productos engañosos, aunque recalca que la máxima hermosura era suya sin afeites, sin quimeras, lo que finalmente relaciona que es como debe surgir y ser el amor. Sin embargo, perfila un vicio denunciado con frecuencia en la época, sobre todo en relación a la mujer, que es la vanidad; cualidad negativa que las mujeres potenciaban según los moralistas del momento intentando verse más bellas de lo que son, empleando ese tipo de productos, aseándose y acicalándose para ser más atractivas, lo cual podría llevarnos a pensar en la propia Betsabé y en como su vanidad la lleva a traicionar a su marido al despertar los deseos en el rey David.

\section{ALCOHOL Y BETSABÉ: BELLEZA O VANIDAD}

Decíamos que ha habido unanimidad a la hora de relacionar los espejos de Alcohol y Betsabé dentro del programa iconográfico de la capilla de la Virgen de Guadalupe en las Descalzas Reales, sin embargo, pocos argumentos iconológicos se han buscado para justificar la relación que puede existir entre las representaciones de ambas mujeres. A tenor de lo que veíamos en Historia y dialogos de Iob de Joseph Gallo, la relación entre estas dos mujeres que se aprecia a simple vista es la de poseer ambas una gran belleza. En la descripción que hace Gallo de Alcohol veíamos que habla de una belleza tan exultante que parecía estar potenciada por algún tipo de afeite que pinte o decore el rostro pero que, a pesar de las apariencias, es una belleza sin engaños, que no está ensuciada por la vanidad.

Es precisamente la vanidad de Betsabé, su atrevimiento de mostrar su cuerpo desnudo y el engaño a su esposo, lo primero que nos dice de ella el escritor Martín Carrillo, en sus Elogios de mugeres insignes... (1627), fuente principal para la elaboración de la capilla de Sor Ana Dorotea, en el que se encuentra un elogio dedicado a las virtudes de Betsabé. No obstante, como decíamos, Carrillo advierte desde el principio del Elogio XXX, que a muchos les llamará la atención que esta esposa de David tenga un espacio reservado a sus virtudes y que se la destaque como mujer insigne; pero especifica que, a pesar de sus pecados y vicios, Betsabé fue una buena madre para del rey Salomón y buena esposa para el rey David, por lo que simplemente por eso es merecedora de alabanzas.

De este modo, Carrillo expone:

Con estos ejemplos consta la poca honestidad de Bersabe. En ponerse desnuda, en parte donde la pudiera ver el rey David y como él la vio, la podían ver otros, principalmente siendo mujer hermosa y no como quiera, sino en grado superlativo, dicen las Escrituras. Dice San Chrisóstomo que cuanto es una mujer más hermosa tiene mayor obligación de guardarse, porque está en mayor peligro, y con facilidad se juzga contra ellas, y aunque sean castas dan siempre de sospechar. (Carrillo, 1627: 128). 
Y añade: «No lo hizo así Bersabe, que antes se aderezaba y lavaba, y se puso en una parte donde la pudiesen ver, y por esta primera razón la condenaron muchos». (Carrillo, 1627: 129).

Por lo tanto, y aunque más adelante en su Elogio destaca las virtudes de Betsabé como madre buena y justa de Salomón y por ser parte del tronco genealógico del Salvador, Carrillo critica la falta de pudor y exceso de vanidad de Betsabé sobre todo en referencia a la escena del baño. Por este motivo, la escena escogida por Sebastián de Herrera Barnuevo y Sor Ana Dorotea, a pesar de que la más conocida y recurrentemente representada de la historia es la del momento en que David, desde su palacio, observa a Betsabé, quien totalmente desnuda se aderezaba y lavaba, provocando que el rey se enamorase perdidamente de ella, es la de un momento que subraya su cualidad de madre del rey Salomón [fig.2], representándola coronando a su hijo, lo cual se destaca también con la filacteria que la acompaña: Per me imperant. ${ }^{7}$ Sin embargo, el hacer pareja con Alcohol, en el lado opuesto del intradós del arco, podría funcionar como recordatorio para quien observase de que Betsabé había cometido faltas que no son dignas de una buena mujer y la gracia de Dios; es decir, Betsabé, aun siendo representada en un momento de virtud que justifica su presencia en el altarretablo, representaría la belleza externa, la pura vanidad, mientras que Alcohol [fig.3], que porta en la mano una piedra, en una posible alusión a esos afeites que se empleaban por las mujeres para embellecer su rostro, poseía una hermosura pura e interna, regalo a su padre por los trabajos realizados. Alcohol, aunque su rostro pareciese pintado, bruñido, poseía una belleza sin trampa ni cartón, ejerciendo, de este modo, como contrapunto de Betsabé, y adivirtiendo de la dicotomía existente en la pintura de la mujer con la que hace pareja entre vanidad y virtud, también con su filacteria: Dilatat oculus [Abre los ojos].

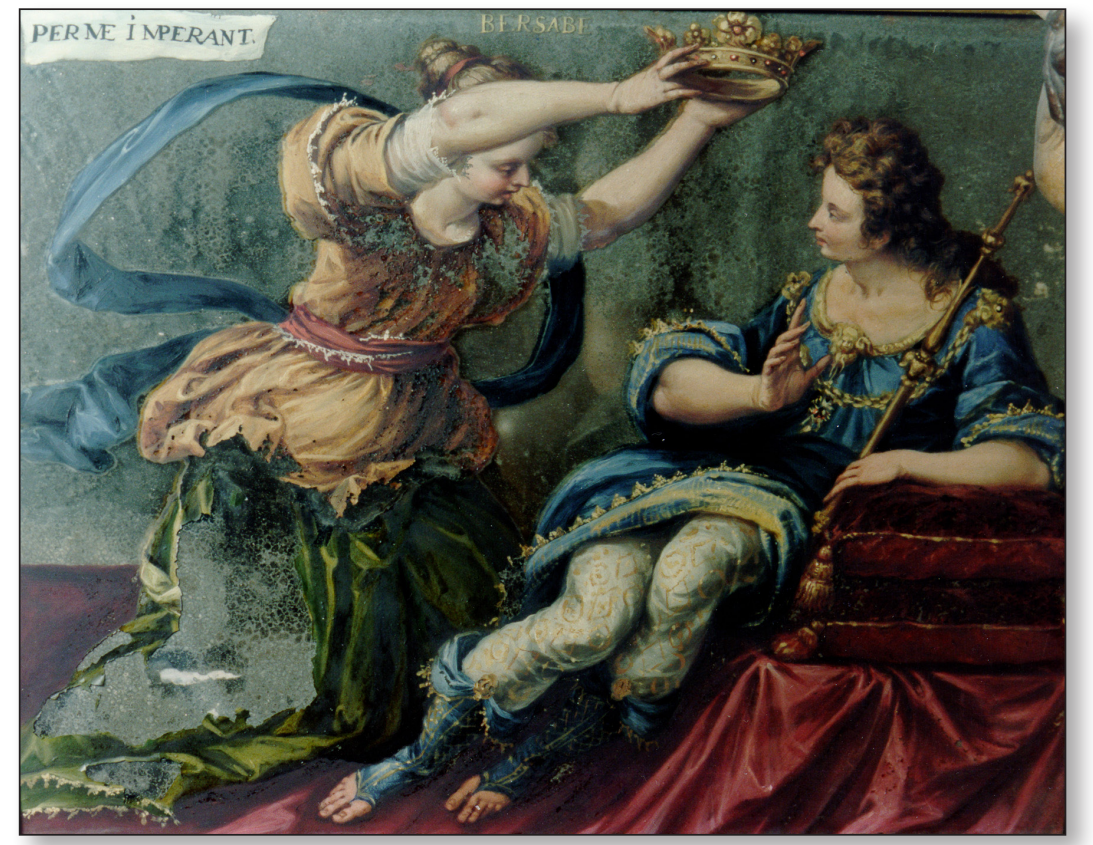

Fig. 2. Sebastián de Herrera Barnuevo, Betsabé coronando a Salomón. Madrid, Monasterio de las Descalzas Reales (Patrimonio Nacional).

7. La traducción sería «Reinan por mí», lo cual hace referencia a que a pesar de sus pecado el rey y ascendiente de José, esposo de la mismísima María Santísima (Carillo, 1627: 141; Sánchez Hernández, 2014: 504-505). 

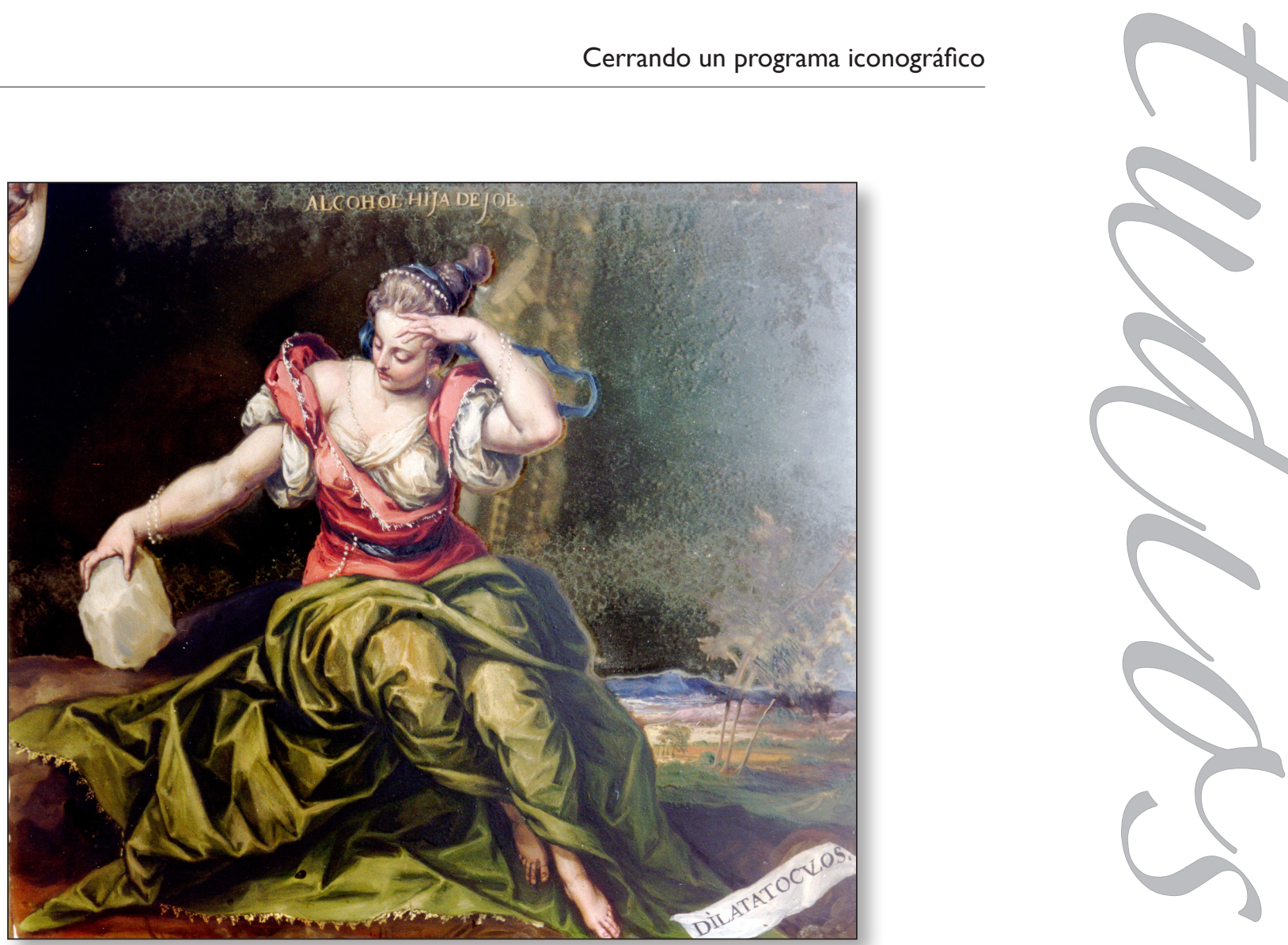

Fig. 3. Sebastián de Herrera Barnuevo, Alcohol, hija de Job. Madrid, Monasterio de las Descalzas Reales (Patrimonio Nacional).

\section{DÍA, HIJA DE JOB, Y LA INMACULADA CONCEPCIÓN: POST NUBILA, PHOEBUS}

«Gobierna tras las nubes» es lo que significa la traducción al castellano la filacteria de Día o mañana, hija de Job [fig. 4], que corona el conjunto de la capilla, ocupando la clave del arco de medio punto. Este espejo se encuentra en eje con el de la Inmaculada Concepción y sería totalmente lógico que ambas mujeres formasen pareja como sugieren Sánchez Hernández (2014) y Alba y Seijas (2016); sin embargo es necesario ahondar en los motivos de esta relación iconográfica.

Decía Joseph Gallo que Día igual que la Virgen era hermosa como la aurora, el Sol y la Luna, y que su nacimiento había supuesto para Job el amanecer tras la larga noche de sus trabajos. Tanto la aurora, como el Sol y la Luna, son motivos estrechamente relacionados con la iconografía mariana inmaculista, y lo mismo lo es el hecho de gobernar tras las nubes o ser el amanecer que trajo el día, la luz de nuevo, tras la noche en la que había sumido a la humanidad el pecado original.

El día, mañana o la paloma -otra acepción del nombre de la hija de Job- acompañan a las representaciones inmaculistas en forma de luz, representan la esperanza que trae a la humanidad con su pureza sin mácula, idea que se recoge constantemente en los Mariales o escritos de la época dedicados a las glorias de la Virgen, en los que se vincula, en diversas 
ocasiones, a ésta con la historia de Job y sus hijas, normalmente en relación al nacimiento de la Virgen y a la luz que trae tras las nubes, después de la noche oscura del pecado. Así se observa en el Marial de Cristóbal de Avendaño (1629):

Pero a propósito de su hermosura esta grande Señora alegró a Dios, y destierra los pesares, que le da los pecadores, dice la Escritura, que el Cielo dio a Job, después de todos sus trabajos tres hijas, las más hermosas, que hallaron en aquellos tiempos [...] Para que con su hermosura desterrasen totalmente la tristeza que su padre había tenido en los trabajos pasados. (De Avendaño, 1629: 171).

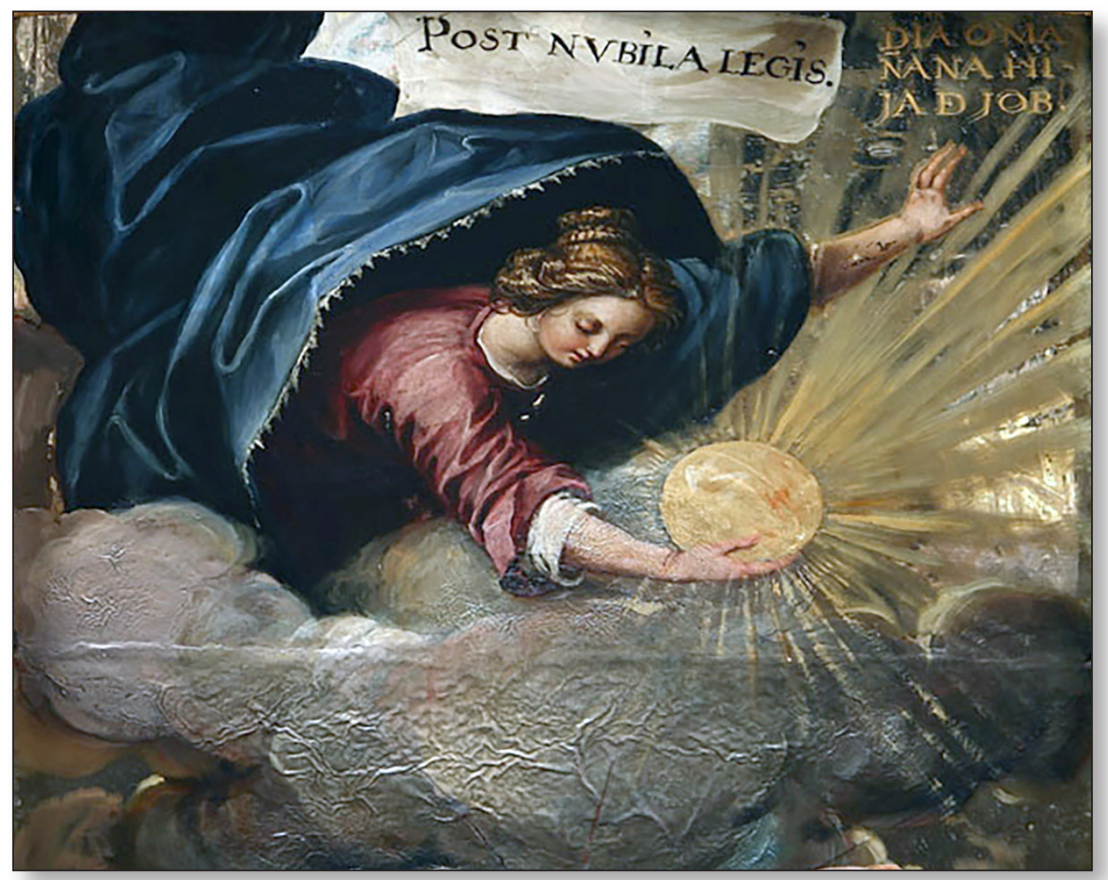

Fig. 4. Sebastián de Herrera Barnuevo, Día o mañana, hija de Job. Madrid, Monasterio de las Descalzas Reales (Patrimonio Nacional).

Idea que se amplía en el Promptuario espiritual escrito por la pluma del portugués Ignacio Coutinho (1647):

A la primera la llamó Día; a la segunda Casia a la tercera Cornustibio [...] La primera Día significa lo mismo que la palabra suena; esto es día, con lo cual dice el Santo Job alusión al primer estado próspero y feliz en el que se vio, como Príncipe y señor que era que todos le estimaban y querían y adoraban: y por cuanto este florido estado fue víspera de otro muy opuesto, no menos miserable y abatido, por ello con razón la llamó Día: el cual siendo así que de su cosecha tiene claro y alegre; con todo siempre la luz viene a parar en tinieblas, y la claridad en oscuridad, y mientras dura la noche todas las cosas están escuras llorando, lamentando la falta de luz, que tan presto acabó, por lo que llamar a esta Día es significar que sus glorias fueron breves, sus felicidades de poca duración que es como si durasen un solo día. (Coutinho, 1647: 283). 
Este mismo autor añade:

Recogiendo todo lo dicho, quiso el Santo Job con tales nombres recordarnos el último estado en que Dios le había puesto: volviéndole no solamente los bienes que le había quitado, sino dándoselos acrecentados, convirtiendo otra vez en día claro la noche escura de sus trabajos [...] Cuando no os acatáis, vuelve el día con su hermosura primera, con su ornato antiguo y la misma luz, la cual naciendo de la noche muerte suya, y resucitando de las tinieblas, las deshace y viene a ser y quedar el día heredero de sí mismo [...] El Señor va alternando siempre los males y los bienes, y cuando parece que los tiene más desamparados, y más empleados en ello su rigor, todos esos nublados y oscuridades en breve se deshacen y vuelve el día claro y sereno, los males se convierten en bienes, y las desgracias en venturas. (Coutinho, 1647: 284).

Tras las nubes siempre vuelve a salir el Sol, vuelve la claridad del día. Esta idea se repite y enlaza con el nacimiento inmaculado de la Virgen y el otro nombre que se da la hija de Job en las Descalzas, Mañana, en la obra de Diego de la Vega Prerrogativas y Excelencias de la Virgen Nuestra Señora (1616):

[...] dijo Malaquías: Nacerá al mundo para los que temen a Dios un Sol de justicia. La Virgen por el consiguiente es llamada mañana, que es con la luz y el resplandor de su gracia, comenzó a contrastar las tinieblas del mundo. Dijeron los Ángeles: ¿Quién es esta que nace hermosa como la mañana? Conforme a esto querrá decir Job: Esperar a la culpa original, que introdujo Adán nuestro padre en el mundo, a la verdadera luz de Cristo, y no le verá de sus ojos; y esperar desear y anhelar a la hermosa mañana, que es la Virgen su madre. (De la Vega, 1616: 6).

Identifica directamente a la Virgen con el nombre de Mañana, el segundo apelativo que se le otorga a la hija de Job en su inscripción de letras doradas en el espejo, nombre que no aparecía en las traducciones del Libro de Job o sus comentarios y exposiciones, pero que se relaciona totalmente con la Virgen y su llegada para iluminar como hermosa mañana, que aparta la culpa original con su luz que destierra las tinieblas, gobernando tras la nubes. El mismo concepto que recoge Juan Martínez de Llamo en el Marial de las fiestas de Nuestra Señora y su Concepción Purísima (1682) pero en este caso empleando el nombre de día para María y empleando el motivo del Sol para justificar que es un día sin noche:

Convenientemente dice Ánglico, por el día es entendida María, no día como quiera, día clarísimo, a quién no sucede noche, ni obscuridad alguna [...] El Sol es causa del día, y así cuando un lugar estuviere más cercano y vecino al Sol, tanto allí el día es más claro: y aunque en la parte inferior al día suceda la noche, por la obscuridad de la tierra que se interpone, de donde proviene, que una parte impida la iluminación de la otra; en la parte superior de la Esfera del Sol, siempre es día clarísimo, y perpetuo. Así sucede en los demás Santos, que han sido santificados en el vientre de sus madres, que aunque sean ilustrados por el Sol de Justicia de Cristo, fueron días pero no tan claros que no precediese en ellos la noche y la oscuridad de la culpa. No así en María, que fue como la Esfera del Sol círculo de él, día claro y lucidísimo, sin interposición de obscuridad [...] En María su Concepción es día clarísimo, no se interpongan ni sombras de culpa, que siendo día perpetuo sin noche, no ha de tener obscuridades de culpa, ni por un instante, que es la más cercana al Sol, y es todo luces de gracia. (Martínez de Llamo, 1682: 18).

Día o mañana, hija de Job, coronando el arco de la capilla de la Virgen de Guadalupe en eje con el espejo octogonal de la Inmaculada Concepción, porta precisamente esa esfera solar de la que habla Martínez de Llano, simbolizando la carencia de mácula en la concepción de María, la cual, a diferencia de los demás santos que, aunque iluminados por la luz de 
Cristo, fueron oscurecidos por las sombras del pecado en su concepción, está libre de toda nube de culpa. La Virgen es Día claro como la esfera del sol a la que no puede acercarse ni la sombra de la noche.

\section{CERRANDO UN PROGRAMA ICONOGRÁFICO}

En definitiva, las tesis de Sánchez Hernández (2014) y Alba y Seijas (2015) sobre la correlación entre los espejos, por un lado, de Alcohol y Betsabé ${ }^{8}$ y, por otro, de Día y la Inmaculada Concepción, queda fuera de toda duda.

El punto de unión entre Alcohol y Betsabé sería la belleza extrema pero en una relación de contrapunto; mientras la belleza de Queren Happuk nos habla de un regalo divino puro y carente de pecado que se acerca a la perfección, la hermosura de Betsabé y su afán por incrementarla, aderezándose en el baño, la condujo al pecado, al traicionar a su esposo con el rey David. Sin embargo, la elección del tema de Betsabé, representada coronando a Salomón y no en ese momento de encarnación de la vanidad femenina, le otorga también el valor de mujer insigne, que a pesar de haber pecado supo arrepentirse y reconducir sus actos, siendo una gran madre para el rey.

Por su parte, la relación entre Día o Mañana, portando en sus manos el sol, y la Inmaculada Concepción, no es otra que la luz; el resplandor que invadió a Job cuando su primera hija Jemima llegó a su vida después de sus trabajos, se equipara en esta concomitancia con la Inmaculada Concepción, con el destello que supuso para la humanidad el nacimiento de la Virgen, concebida sin pecado, tras la prolongada noche que había provocado el pecado original. Ambas encarnan la mañana, el amanecer, el alba, la aurora; una irradió al padre y la otra a todos sus hijos.

De este modo, el complejo programa iconográfico elaborado por Sor Ana Dorotea y ejecutado magistralmente por Herrera Barnuevo se cerraría completamente, denotando aun con mayor firmeza, si cabía, la brillantez a la hora de plantear su discurso en la capilla de la Virgen de Guadalupe. Ni un solo detalle fue dejado al azar y cada una de sus elementos compositivos trabajan conjuntamente en un juego de interrelación concebido para destacar lo virtuoso de la condición femenina, teniendo como receptor del mensaje a la congregación de clarisas descalzas, quienes lo debían contemplar cada día en su camino hacia el coro, viendo en aquellas mujeres un espejo en el que mirarse, un modelo de virtudes, ya que la propia materialidad de las pinturas así lo sugiere (Álvarez Seijo, 2018: 143-167).

Un programa virtuoso, de virtuosas mujeres, para fomentar las virtudes de sus devotas espectadoras.

8. Apuntada esta relación ya en 1966 por Wethey y Sunderland y sostenida en 2010 por Díaz García. 


\section{FUENTES}

Avendaño, C. [1629]. Marial de las fiestas ordinarias y extraordinarias de la Madre de Dios, Señora nuestra, con sermones al fin de sus celestiales padres. Dedicado a la Magestad del Espíritu Santo, infinito Dios, y Señor de Cielo y Tierra, y de lo visibl e y lo invisible. Compuesto por el padre maestro FR. Christóbal de Avendañi, de la Orden de Nuestra Señora del Carmen, Difinidor de Provincia de Castilla la Vieja, natural de la muy noble ciudad de Valladolid, Valladolid, Imprenta de Juan de la Rueda.

CARrillo, M. [1627]. Elogios de las mugeres insignes del Viejo Testamento, Huesca, Pedro Bluson.

Coutinho, I. [1647]. Promptuario espiritual traducido por Fr. Fracisco Palau, Prior del Convento de Santa Catalina de Barcelona, Madrid, Imprenta de Pedro Coello.

De La Vega, D. [1616]. Prerrogativas y excelencias de la Virgen nuestra Señora, fundadas sobre los Evangelios que predican sus festividades, por nombre marial. Dedicado a la misma Virgen y Reyna del Cielo, Alcalá de Henares, Imprenta de Juan Gracián.

GALLO, J. [1621]. Historia y diálogos del santo Job con explicación literal y moral de todos sus capítulos según versiones de Vatablo, Paganino, Parafraste y los Setenta, Burgos, Imprenta de Pedro Huydobro.

León, Fr. L. de [1779]. Exposición del Libro de Job, II, Madrid, Imprenta de Pedro Marín.

Ligorio, A. Ma . de [1885]. Las Glorias de María, Barcelona, Librería Religiosa.

Martínez de Llamo, J. [1682]. Marial de las fiestas de Nuestra Señora desde su concepción purísima hasta la festividad más moderna de sus desposorios con el patriarca San Joseph, Madrid, Imprenta de Antonio Zafra.

Quevedo y Villegas, F. [1774]. «La constancia y paciencia del santo Job, en sus pérdidas, enfermedades y persecuciones» en Vida y obras póstumas de Francisco de Quevedo y Villegas, caballero del hábito de Santiago, secretario de su Magestad y señor de la villa de la Torre de Juan Abad, Madrid, Imprenta de Sancha.

Rigual, J. [1797]. Oficio parvo de Ntra. Sra. la Santissima Virgen, Madrid, Imprenta Real.

Scio de SAN Miguel, F. [1852]. La Santa Biblia traducida y anotada al español por el padre Phelipe Scio de San Miguel. Antiguo Testamento, Madrid, Gaspar y Roig.

\section{BIBLIOGRAFÍA}

[1975]. Nueva Biblia española, J. Alonso Schökel y J. Mateos (trad.), Madrid, Ediciones cristiandad.

[2010]. La Sagrada Biblia. Traducida de la Vulgata Latina al español, F. Torres AmAt (trad.), Barcelona, Plutón ediciones.

Alba, A. y Seijas, G. [2015]. «Las mujeres fuertes de la Biblia y su pervivencia en la pintura española del siglo XVII» en G. Seijas de los Ríos-Zarzosa (ed.), Mujeres del Antiguo Testamento: de los relatos a las imágenes, Aletheia, Estella, Editorial Verbo Divino, 93-124.

Álvarez Seijo, B. [2018]. «En-Clave de género. Las mujeres fuertes del Antiguo Testamento en la Capilla de la Virgen de Guadalupe de las Descalzas Reales», Anuario del Departamento de Historia y Teoría del Arte, 29-30, 143-167.

Díaz García, A. [2010]. "Sebastián de Herrera Barnuevo (1619-1671). Obra pictórica", Cuadernos de arte e iconografía, XIX, 37, 9-251. 
Gutiérrez Mueller, B. [2013]. «Exégesis barroca del Libro de Job: Luis de León, Gallo y Quevedo", Atalanta: Revista de las letras Barrocas, 1, 2, 5-30.

SAn Jose Lera, J. [1992]. "Sobre el códice salmantino de la «Exposición del Libro de Job», de Fray Luis de León: problemas textuales y resultado estilísticos», Edad de Oro, 11, 161-174.

SÁnchez Hernández, Ma L. [2014]. «La Capilla de Guadalupe en el Monasterio de las Descalzas Reales» en G. Franco Rubio y Ma A. Pérez SAmper (eds.), Herederas de Clío. Mujeres que han impulsado la historia, Sevilla, Mergablum, 493-513.

SÁnchez Hernández, Ma L. [2016]. "Católicas y Reformadas: apuntes iconográficos de dos formas de relación bíblica» en M. L. Giondano y A. VAlerio (eds.), Reformas y Contrarreformas en la Europa católica (siglos XVI-XVII), Estella, Verbo Divino, 133-154.

Splitter, R. P. [1983]. "Testament of Job» en J. H. Charlesworth (ed.) Old Testament Pseudepigrapha, New York, Garden City, vol. 1, 829-869.

Wethey, H. y Sunderland Wethey, A. [1966]. "Herrera Barnuevo and his Chapel in the Descalzas Reales», The Art Bulletin, 48, 1, 15-34. 